\title{
MONOZYGOTIC BOVINE QUADRUPLETS
}

\author{
H. P. DONALD, W. S. BIGGAR and D. M. LOGAN \\ Animal Breeding and Genetics Research Organisation, Edinburgh
}

Received Io.v.50

ON the 27th January 1949, a Friesian type cow called Peggy, and belonging to $\mathrm{Mr}$ William Youngs of Sankence Farm, Aylsham, Norfolk, produced four bull calves. After undergoing considerable publicity for a few days, Peggy died, but the calves survived and were purchased by the Agricultural Research Council, and transferred to the Cattle Breeding Research Farm at Cold Norton in Staffordshire. These calves are remarkable, not only because quadruplets are unusual in cattle, but also because they were born alive, and were all of the same sex. Furthermore, they appear to be the first recorded set judged to be of monozygotic origin. A somewhat detailed account of them, therefore, appears desirable. Unfortunately, two of the calves died a few weeks after purchase, so that a comparison of late developing features became impossible.

The evidence on which the diagnosis of one-egg origin is based is as follows. Except where otherwise noted, all remarks apply equally to all four calves.

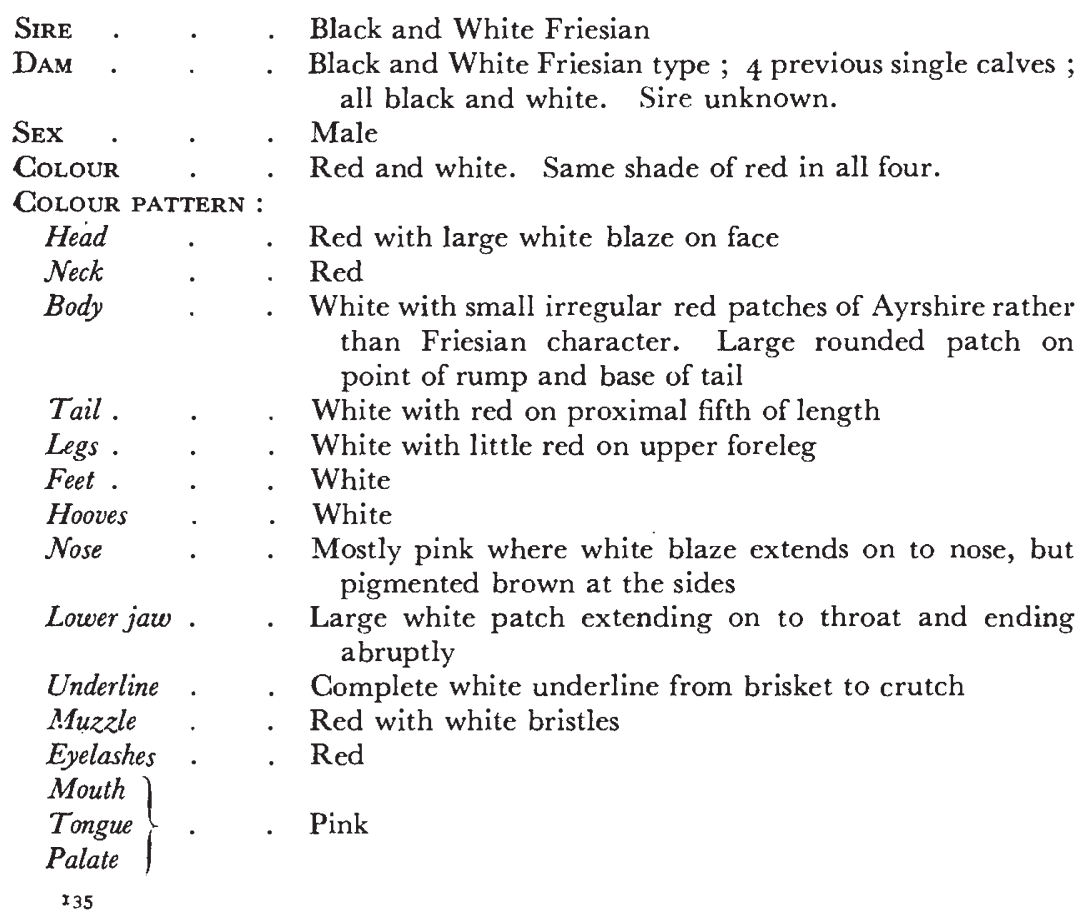




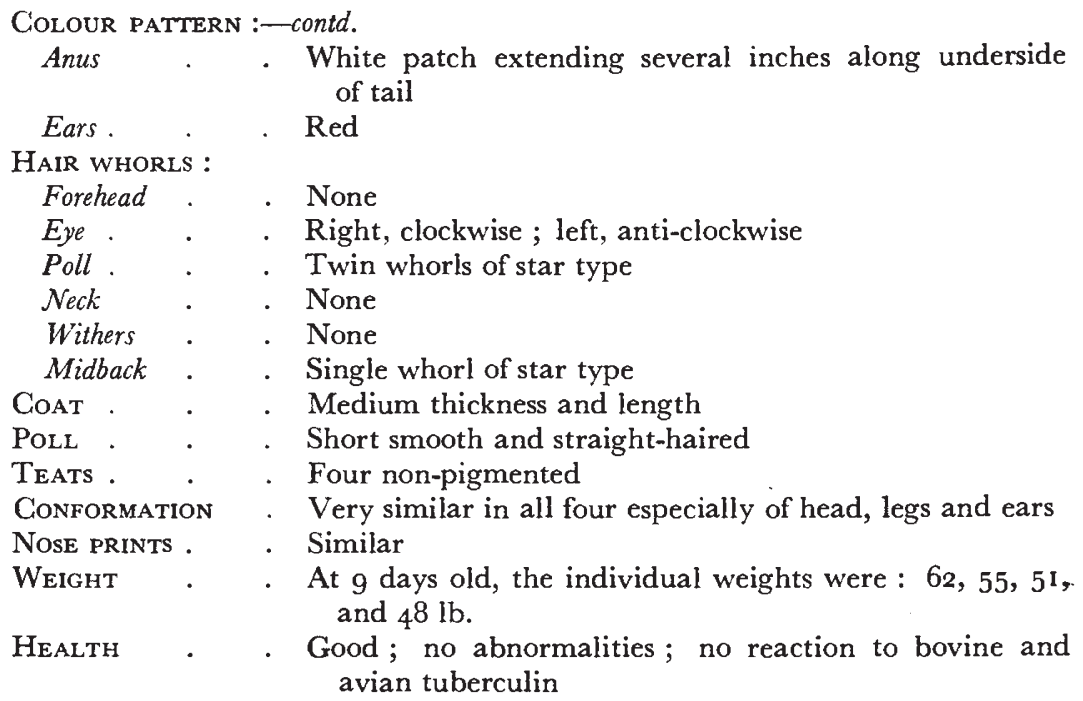

It will be noticed that although both parents were of Friesian type, all the calves were red. The chance that any set of quadruplets or of four consecutive single calves from Friesians heterozygous for red will be all males and all red is once in $16 \times 256$ or 4096 such sets. Since it is immaterial from the point of view of judging monozygosity whether the calves are all male or all female, this figure should be halved, i.e. 2048. On the same line of reasoning, it might be considered that the colour as. well as the sex of one calf is irrelevant, in which case the appropriate chance is once in $5^{12}$ sets if the first calf is red. The set described might be just such an isolated case, so other details become important.

The colour pattern is characteristic of Ayrshires, not Friesians. This suggests either that Ayrshires occur in the ancestry of both parents or that the cow had Ayrshire blood and was actually mated to an Ayrshire bull, and not, as supposed, to a Friesian bull. The owner reported that the cow was purchased as a non-pedigree Friesian and was sure that the Friesian bull, which was homebred, was the sire. It has sired other red calves in the same herd, and it could conceivably have some Ayrshire blood.

Cole and Johansson (1948), however, show photographs of six red and white Holstein cows, all of which had pigmented areas with ragged "Ayrshire" edges. Red and White $F_{2}$ segregates from Holstein $\times$ Angus crosses were similar. They postulate therefore that the "ragged " type of pattern is connected with the kind of pigmentation. The fact that the quadruplets were red may thus adequately explain their ragged pattern and render unnecessary any assumptions about Ayrshire ancestry or any doubts about the real sire. The case for monozygosity is then weakened to the extent that concordance in pattern type carries no weight.

Concordance in the distribution of pigmented areas is a property independant of the type of pigment and remains a striking feature 
of the calves. As can be seen from the photographs (plate II) there was a very close similarity in the shape and size of the white blazes on the faces, and of the white area on the lower jaws and throats of the otherwise red heads and necks. There were also red patches on the hind quarters extending for the same distance along all four tails. The similarity of these four red rump patches is enhanced by the fact that in each calf there was a white patch surrounding the anus, and extending some inches along the underside of the tail. Full-sibs showing this overall concordance in pattern would be unusual. The photographs show clearly the parent-offspring differences in pattern, particularly in respect of the white blazes on the heads which in the calves are very uniform in shape and size, and in extent considerably transgress the parental characters. In spite of these resemblances, however, the calves showed differences in the shape, size and distribution of coloured areas on their sides, all eight sides being easily distinguishable.

Hair pattern was the same in each calf. It is quite characteristic of calves in the West Midland region of England, where dairy cattle are predominantly of Friesian and Shorthorn extraction, to have no whorls on the neck and withers, to have a single star-type whorl in the mid-back area, and to have a whorl (or better, a vortex) of hairs slightly behind and above each eye, so that no significance attaches to lack of variation in these respects. A single star-type forehead whorl, however, located between the eyes, is found on the majority of calves. Only seven calves among four hundred pairs of fraternal twins from a very mixed population showed no whorl, and each of these seven were associated with mates bearing whorls. That all the quadruplets should be without forehead whorls is therefore arresting. Too much importance, however, should not at present be placed on this observation. Not much is known about the amount of genetic variation in whorl type or number, and, moreover, there is some reason to suspect that whorls invisible at birth may develop with age. These reservations by no means rule out the possibility that some animals will never develop these face whorls. Such animals have been frequently seen among mature Jersey and Aberdeen-Angus cattle and occasionally in other breeds. Many Zebu cattle in the United States have been examined without finding any which had face whorls.

The quadruplets had two poll whorls each, although the 400 pairs of fraternal twins mentioned above showed that 71 per cent. of the calves had one such whorl and 29 per cent. had two. Of the 400 pairs, 34 were unclassifiable for various reasons, and of the remainder only 22 per cent. were discordant which is about half the proportion expected to be discordant on the basis of a purely random association of one with two poll whorls. Here again the genetic situation is obscure but the evidence of a tendency for two-egg twins to be alike creates a presumption that one-egg sets ought to be alike. Had the quadruplets differed, doubts about their monozygosity would have 
arisen, but how serious those doubts should have been is as yet a moot point.

Concordance in teat numbers and coat character, including the long hair of the poll, is likewise at present of limited interest. The important point is that no differences were found. All that can be said of the nose prints is that they too were alike, when they might have shown marked differences. So far, no objective method of describing and classifying nose prints, such as that suggested by Nadai (1949), has been tried.

Nine days after birth, the weight of the calves varied between 48 and $62 \mathrm{lb}$. Total weight of calf produced by the dam was, therefore, about $210-220 \mathrm{lb}$., which is about $2 \frac{1}{2}$ times the normal weight of a single Friesian calf. The calves were all sleepy and sluggish, especially the smaller ones, and remained so.

At ten weeks old, the third calf, in order of birth weight, died at $76 \mathrm{lb}$. weight. It had hardly grown for two months. Two weeks later, the calf that was smallest at birth died after struggling slowly to 103 lb. Although the immediate cause of death in both cases was peritonitis and complications following scouring, the real cause seemed to be persistent low vitality which no practicable kind of care and attention could overcome. At nine months old, the two survivors were still notably slow and unaggressive for bulls of that age.

Although subjective and impossible to convey accurately in writing, the judgment of experienced persons about conformation, particularly of the head, is valuable in diagnosis. No doubt is felt about the quadruplets in this respect, nor have the surviving pair developed any features which would suggest a revision of the original judgment. In conformation and behaviour, they are as alike at one year old as well-established pairs of monozygotic twins.

To sum up on the question of monozygosity, it may be said that, as with the diagnosis of one-egg twins, there is no single piece of evidence which is conclusive. There are, however, so many characters in which the calves might be expected to vary, especially sex, colour and pattern, that the degree of concordance shown here leaves very little doubt of a monozygotic origin. It would have been interesting to study the blood groups, but this was not possible. Had the calves been concordant in this respect, the case for monozygosity would have been strengthened, but not absolutely settled, for although quantitative methods are available by which one-egg and two-egg twins can be distinguished (Stormont, personal communication) the faint possibility would remain that the calves all inherited the same genotype in respect of the blood groups studied.

\section{DISCUSSION}

Since there are no satisfactory vital statistics for cattle in Britain, the frequency of multiple births is not known. In man, the frequency approximates to that required by Hellin's Law, namely $\mathrm{P}^{n-1}$ where 
$\mathrm{P}$ is the frequency of twins and $n$ is the number in the multiple births (Newman, 1942). Quadruplets would have an expected frequency of $\mathrm{P}^{3}$. If this law is applicable to cattle, quadruplets should appear once in a million births in a population with a I per cent. twinning rate, and once in half a million births with a $I \cdot 25$ per cent. twinning rate. Monozygotic quadruplets would occur even less frequently.

Newman has pointed out that Hamlett's ( I935) data on 48 sets of human quadruplets show a marked deviation from the expected sex distribution. Nearly half the sets were all male or all female. This would be expected if one-egg twinning contributed substantially to multiple births. The effect of a combination of one-egg and two-egg twinning would also be a deviation of the same kind, although smaller. from the expected random distribution of sexes within sets.

In order to determine whether bovine quadruplets show any peculiarities of this kind, a search has been made for published records of quadruplets. Table I shows all the suitable material with sex recorded that has been found. Distribution of quadruplets and quintuplets by number of males is as follows :

\section{Quadruplets}

No. of males
No. of sets observed

No. of sets expected

No. of males

No. of sets observed

No. of sets expected

$\begin{array}{cccccc}\mathbf{0} & \mathbf{I} & \mathbf{2} & \mathbf{3} & 4 & \text { Total } \\ \mathbf{I} & 7 & 9 & 2 & 2 & 2 \mathrm{I} \\ I \cdot 3 & 5 \cdot 2 & 7 \cdot 8 & 5 \cdot 2 & I \cdot 3 & 20 \cdot 8\end{array}$

\section{Quintuplets}

$\begin{array}{ccccccc}0 & \mathbf{I} & \mathbf{2} & 3 & 4 & \mathbf{5} & \text { Total } \\ \text { I } & 2 & 3 & 4 & \mathbf{1} & 0 & \text { I I } \\ 0 \cdot 3 & I \cdot 7 & 3 \cdot 4 & 3 \cdot 4 & I \cdot 7 & 0 \cdot 3 & I 0 \cdot 8\end{array}$

Expected numbers have been calculated from $(p+q)^{n}$ using $p=q=\frac{1}{2}$ on the supposition of a $\mathrm{I}: \mathrm{I}$ sex ratio. The actual sex ratio was 39 male : 45 female in the quadruplets and 24 male : 3 I female in the quintuplets. There is nothing in these data to suggest an abnormal sex distribution which might develop from one-egg twinning although that certainly occurs occasionally.

Apart from the quadruplets described in this paper, one-egg twinning has probably occurred in quadruplets reported by Hutt (1930) and in quintuplets by Cook (1948). Indeed a bias may well have been introduced into the foregoing analysis by the inclusion of these sets which might have escaped notice had it not been for suspected one-egg twinning. This bias will probably become stronger in future. From Bonnier (1946) it follows that 8 out of roo pairs of liked-sexed twins will be monozygetic, or roughly 4 per cent. of all twin pairs. If this estimate is appropriate to an overall twinning-rate somewhere between $I$ and 2 per cent., then $I$ in $125^{0-2500}$ pregnancies result in one-egg twins. Fertilised eggs splitting at this rate would not affect appreciably the sex distribution in such a limited number of quadruplets and quintuplets as are presently available. The same line 
TABLE I

Summary of reports of bovine quadruplets, quintuplets and sextuplets

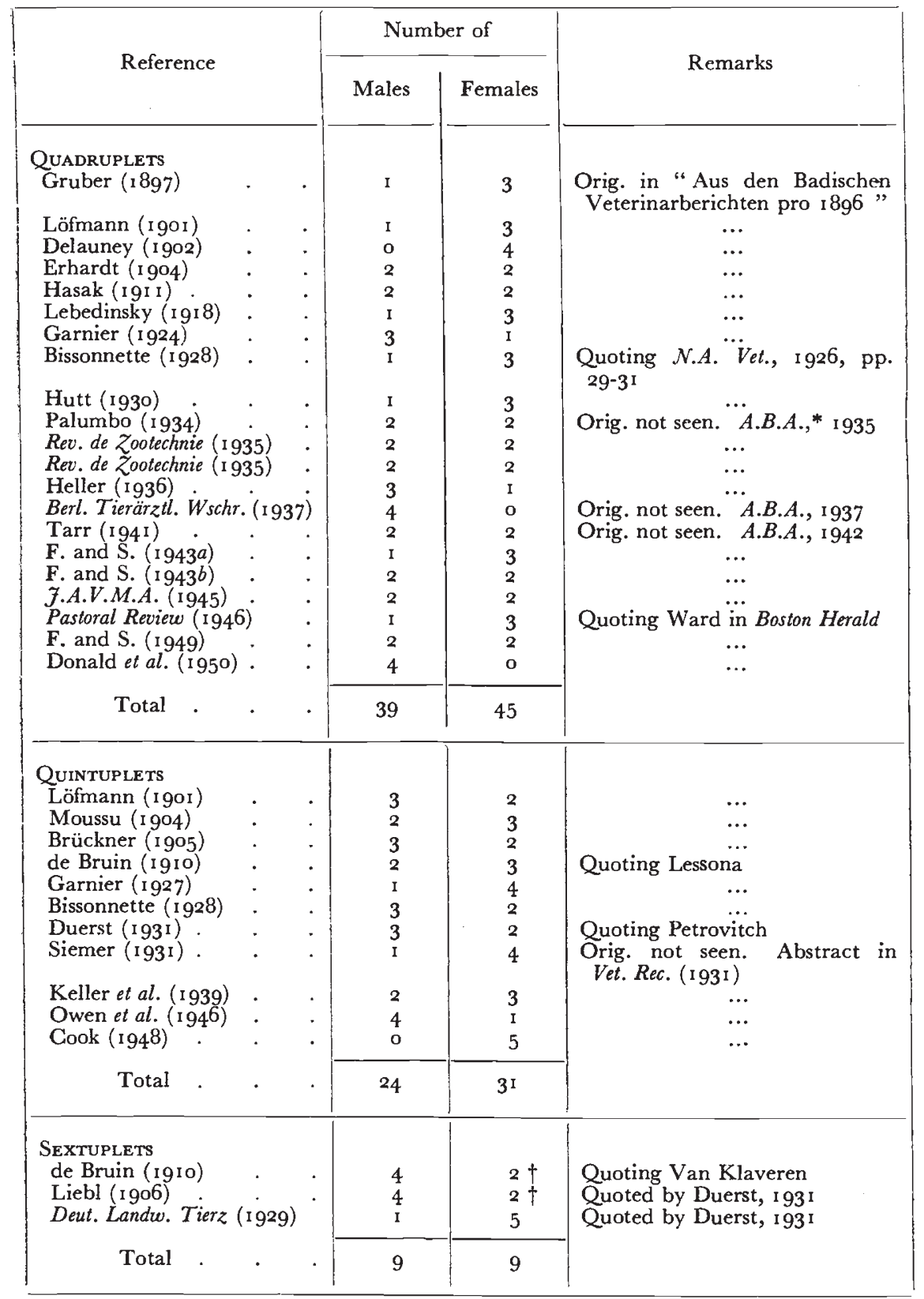

* A.B.A., Animal Breeding Abstracts.

$\dagger$ It is not certain that these cases are different. Van Klaveren's case is cited as having been born 30 days before regular term, and Liebl's case is cited as a full-term birth. Dates of birth were not quoted. 
of thought leads to the calculation that quadruplets derived from one-egg might be expected no oftener than once in $\left(\frac{1}{1250}\right)^{3}$ pregnancies but this is based on the unlikely assumption that the second and third splits are independent of the first.

Two further aspects of table I deserve brief notice. The first is that the sex ratio of all multiple births quoted is 72 male : 85 female -a non-significant departure from that expected for single births (50-52 per cent. males). The second is the ratio of quadruplets to quintuplets, namely 21 : 11 . The latter should occur much more rarely than the former with perhaps I/50-1/10o of the frequency. In other words, the cow population which produced i I sets of quintuplets should also have produced 550-1 100 sets of quadruplets.

\section{SUMMARY}

The first reported set of one-egg bovine quadruplets is described. The sex distribution in quadruplets and quintuplets does not suggest that one-egg twinning is important in their production.

Acknowledgments.--The authors are grateful to Professor H. Lörtscher, Zurich, to the Commonwealth Bureau of Animal Breeding, and to Mr G. Wiener for help in tracing and verifying references.

\section{REFERENCES}

BERLINER TIERÄRZTLICHE WOCHENSCHRIFT. I937. Gesunde Vierlinge von einer Kuh. Berl. tierärztl. Wschr., 53, 388.

BissonNetTe, T. H. I 928 . Notes on multiple pregnancies in cattle with special reference to three cases of pre-natal triplets and the freemartins involved. Amer. F. Anat., 42, 29-6o.

BonNiER, G. I 946 . Studies on Monozygous cattle twins. II. Frequency of monozygous twins. Acta agric. suec. (Stockh.), 1, I47-I 5 I.

BRÜCKNER, - . I905. Fünflinge bei einer Kuh. Berl. tierärztl. Wschr., No. 2, 27. COLE, L. J., AND JOHANSSON, I. I948. Inheritance in crosses of Jersey and Holstein Friesian with Aberdeen Angus Cattle. II. Color and White Spotting. Amer. Nat., 82, 202-233.

cook, R. I 948 . The Bucks County Quintuplets. 7. Hered., 39, i 2, 346-349. DE BRUIN, - i 19 Io. Die Geburtshilfe beim Rind. Vienna.

Delauney, м. н. 1902. Gestation quadruple chez une vache. Rec. Méd. Vét. 9, 490. DeUt. landw. TIERz. I 929. Dtsch. Landw. Tierz., 5, 9 I.

DUERST, J. U. I 93 I. Grundlagen der Rinderzucht. Berlin : Julius Springer.

ERHARDT, - . I I04. Ein Fall von Vielträchtigkeit. Schweiz landw. Z., 32, 73.

F. AND s. I $943 a$. A cow's quads. Fmr. \& Stk.-Breed., 57, 647.

F. AND s. I $943^{b}$. A family of four. Fmr. ES Stk.-Breed., 57, I 324.

F. AND s. I 949 . Quads. Fmr. \& Stk.-Breed., 63, 32 r.

Garnier, J. I924. Gestation quadruple chez une vache. Rec. Méd. Vét., Ioo, 277. GARnier, J. I927. Fécondité exceptionelle chez une vache parthenaise. Rec. Méd. Vét., 103, 485-486.

GRUBER,--. I 897 . Vierlinge bei einer Kuh. Dtsch. tierärztl. Wschr., I897, p. $35^{8}$.

HAMLETT, G. W. D. I935. Human twinning in the United States. Racial frequencies, sex ratios, and geographical variations. Genet., 26, 250-258.

hasak, J. I9II. Vierlinge bei einer Kuh. Tierärztl. Zbl., 34, 489 .

HELLER, O. I936. Vierlinge einer Kuh. Tierärztl. Rdsch., 42, 922-924. 

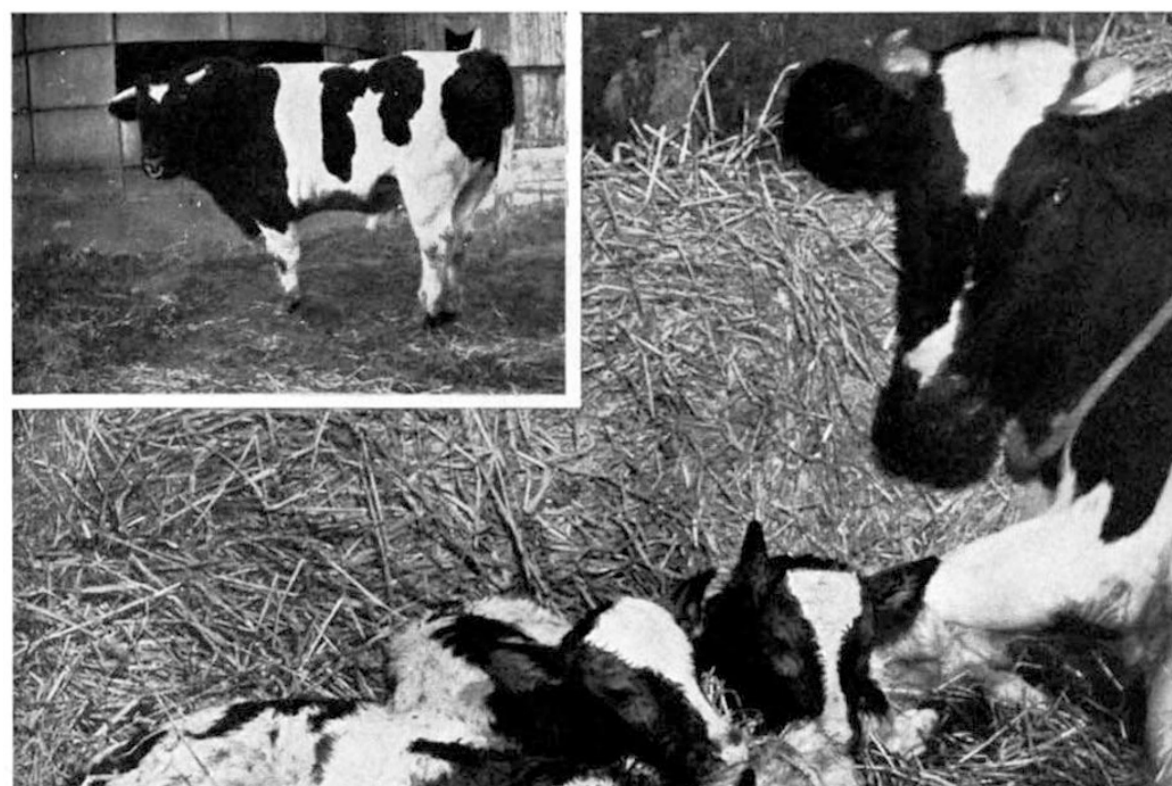

S
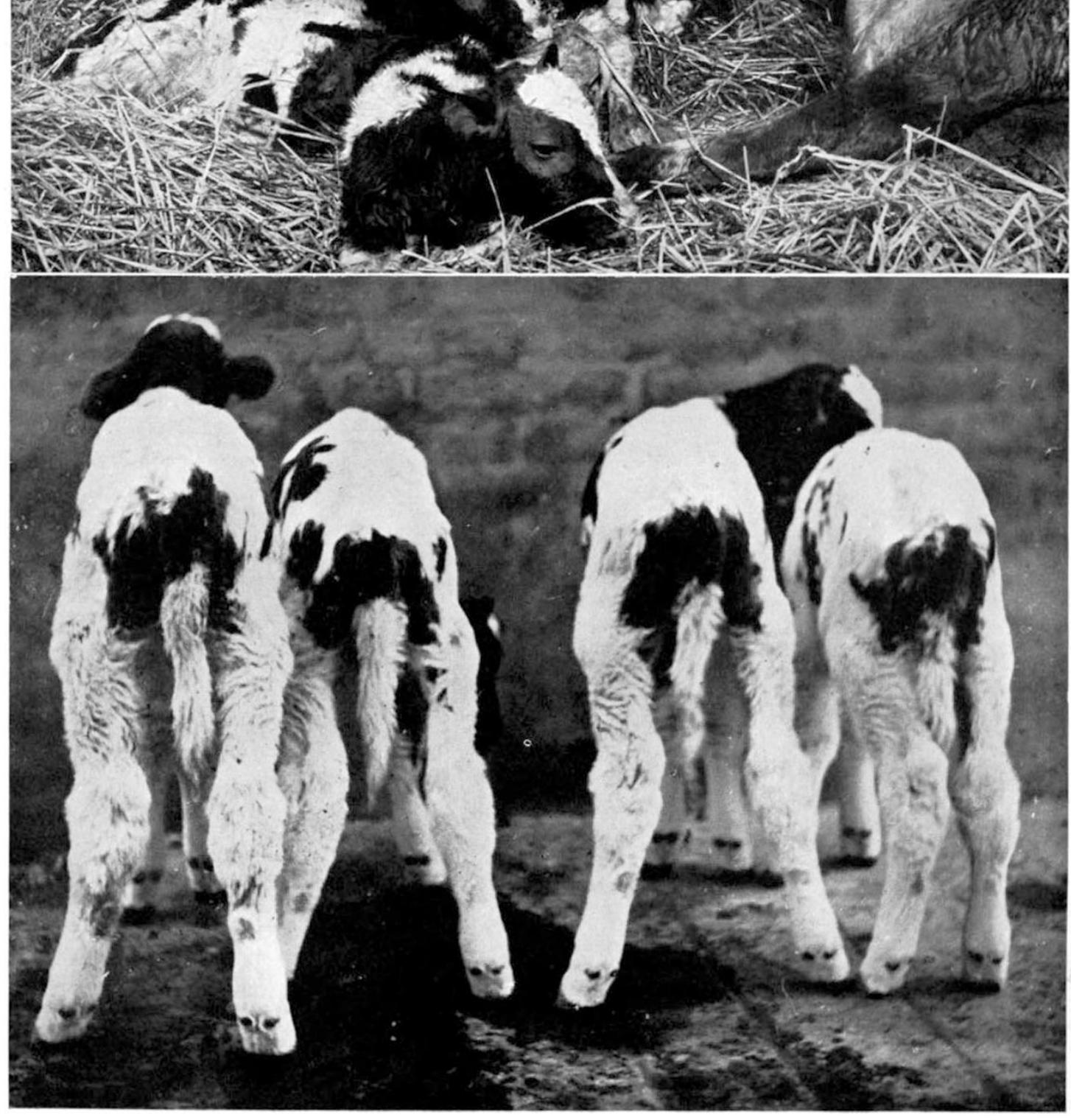
Plate I

Fig. I.-Quadruplets and their dam. (Photograph by courtesy of

Eastern Daily Press, Norwich.) Inset, sire.

Fig. 2.- Rear view of quadruplets showing pattern, coat, and conformation. 
Plate II.-Right and left sides, and heads of the quadruplets. The three photographs in each row refer to one calf. 


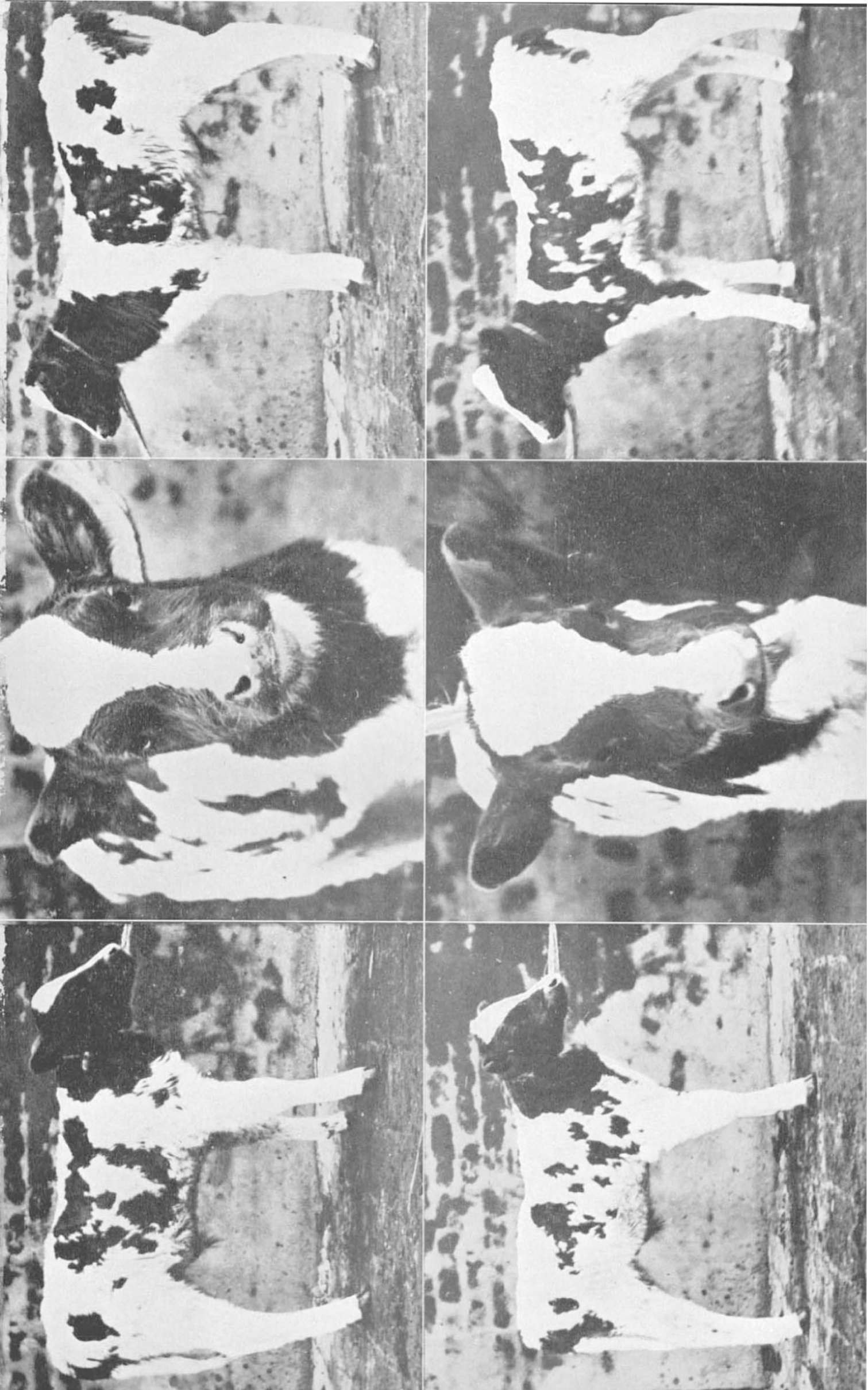


HUTT, F. B. 1930. Bovine quadruplets including twins apparently monozygotic. F. Hered., 21, 339-348.

J.A.v.M.A. I945. Quadruplets in Chicago. 7. Amer. vet. med. Ass., 107, 62.

KELLER, K., NIEDOBA, T., AND SGHOTTERER, A. 1939. Fünflinge bei einer Kuh, untersucht vom Standpunkte der "Zwillingsforschung." Z. Tierz. Zucht Biol., 43,2 I I-230.

LEBEDINSKY, N. G. I9I8. Eine Vierlingsgeburt beim Hausrind. Verh. naturf. Ges. Basel., 29, 6o-68.

LIEBL, - . 1906. Dtsch. landw. Tierz., 1o, 28.

LöfmanN, o. v. IgoI. Seltene Fruchtbarkeit einer Kuh. Berl. tierärztl. Wschr., 1901, p. 730.

moussu, м. г 904 . Quintuple gestation chez une vache. Bull. Soc. cent. Méd. Vét., $5^{8,} 4^{2}$.

NADAI, J. 1949. Untersuchungen über Merkmale für die Eineiigkeitsdiagnostik bei Rinderzwillingen. Z. Tierz. Zucht Biol., 58, 153-241.

NEWMAN, H. H. 1942. Twins and Supertwins. London: Hutchinson.

OWEN, R. D., DAVIS, H. P., AND MORGAN, R. F. I946. Quintuplet calves and erythrocyte Mosaicism. F. Hered., 37, 10, 290-297.

palumbo, v. 1934. Contributo alla casistica dei parti plurigemini. Clin. vet. (Milano), 57, 232-235.

PASTORAL ReView. i 946 . Pastoral Rev., 56, 8, 683.

REVUE DE ZOOTECHNIE. 1935. Un cas particulièrement curieux de fécondité chez une vache. Rev. Zootech., 14, 9, 188.

SIEMER, - . I931 (?). A peculiar occurrence at parturition (Tr. title). Tierärztl. Rdsch., No. 25, p. 447. (Abstract in Vet. Rec., 9, 854.)

TARR, A. 1941. Quintuplets in a cow. 7. S. Afr. vet. med. Ass., 12, 85. 